\title{
Internet Financial Investment Product Selection with Pythagorean Fuzzy DNMA Method
}

\author{
Hongrun Zhang', Huchang Liao ${ }^{1,2, *}$, Xingli Wu' ${ }^{1}$, Edmundas Kazimieras Zavadskas ${ }^{3}$, Abdullah \\ Al-Barakati ${ }^{2}$
}

\author{
${ }^{1}$ Business School, Sichuan University \\ Chengdu 610064, China \\ E-mail.hongrunwell@163.com; liaohuchang@163.com; wuxingliwxl@163.com \\ *corresponding author \\ ${ }^{2}$ Faculty of Computing and Information Technology, King Abdulaziz University \\ Jeddah 21589, Saudi Arabia \\ E-mail.aalbarakati@kau.edu.sa \\ ${ }^{3}$ Institute of Sustainable Construction, Vilnius Gediminas Technical University \\ Sauletekio av. 11, Vilnius LT-10223, Lithuania \\ E-mail.edmundas.zavadskas@vgtu.lt
}

cross'ref $\underline{\text { http://dx.doi.org/10.5755/j01.ee.31.1.23255 }}$

\begin{abstract}
The number of products based on internet financial platform has increased dramatically, but due to the lack of effective regulatory system and the information barrier of investors, product returns have been greatly discounted and investment risks have been greatly increased. How to select high-quality products in internet finance based on several indicators is an important multiple criteria decision making problem. In this regard, this study develops a Pythagorean fuzzy double normalization-based multiple aggregation (PF-DNMA) method to solve the problem of selecting internet financial products. Firstly, the key factors for evaluating internet financial products are identified. Observing that the Pythagorean fuzzy set is an effective tool to express evaluation information, we then extend the original multiple criteria decision making method named the double normalization-based multiple aggregation method to Pythagorean fuzzy environment. The PFDNMA method is characterized by two normalization techniques and three aggregation tools, and thus is effective and robust in solving multiple criteria decision making problems. We deal with an internet financial investment problem by the PL-DNMA method and provide some comparative analyses with the Pythagorean fuzzy TOPSIS and VIKOR methods to illustrate the effectiveness of the proposed method.
\end{abstract}

Keywords: Multiple Criteria Decision Making; Internet Financial Investment; Double Normalization-Based Multiple Aggregation Method; Pythagorean Fuzzy Set; Product Selection.

\section{Introduction}

With the developments of economy and Internet technology, a growing number of Internet financial products are appearing in market, which are conducive to promoting the development of traditional Chinese finance. Besides, these products not only save investors' time, but also increase investors' return on a big probability. In other words, we need to comprehensively select Internet financial products from the future benefits and risk (Merigo \& Gil-Lafuente, 2007). There are many good studies on traditional financial products (GilLafuente, 2005; Merigo \& Gil-Lafuente, 2007). However, the use of emerging technologies adds new risks to financial products (Martins et al., 2014). Therefore, how to select the best product from multiple Internet financial investment products is an important issue for individual investment. This paper aims to evaluate Internet financial products from the perspective of objective experts which provide decision support for investors. Internet financial management is to choose the most effective scheme from multiple investment schemes (Merigo \& Gil-Lafuente, 2007). There are many criteria to measure the performance of Internet financial products (Cai et al., 2015), including financial, security, privacy, performance, social and time risk (Lee, 2009). We need to determine the key factors, and then allocate different weights to these factors for evaluating the investment schemes. That is to say, the Internet financial investment product selection is a typical multi-criteria decision making (MCDM) problem with subjective evaluations because of the qualitative criteria whose values are unable to be measured objectively in crisp values (Stevic et al., 2018).

To handle qualitative decision making problems with ambiguity, Zadeh (1965) proposed the fuzzy set theory to measure the values of qualitative criteria with membership degrees which belong to $[0,1]$. The membership degree can be regarded as the satisfaction degree of alternative $A_{i}$ under criterion $c_{j}$. To describe the uncertain information accurately, Atanassov (1986) introduced the concept of intuitionistic fuzzy set (IFS) which is composed by a membership degree $\alpha$ and a non-membership degree $\beta$ . The IFS aims to describe the preferences from both positive and negative sides. The sum of the membership degree and non-membership degree in an IFS satisfies $\alpha+\beta \leq 1$. However, in practice, because of people's individualized 
cognition, the sum of membership and non-membership degrees is usually greater than 1 . To capture this fact, Yager (2014) introduced the Pythagorean fuzzy set (PFS) whose membership degree $\alpha_{1}$ and non-membership degree $\beta_{1}$ satisfy $\alpha_{1}^{2}+\beta_{1}^{2} \leq 1$. Compared with the IFS, the PFS is flexible to express subjective opinions (Peng \& Yang, 2015). Given these advantages, the PFS has been widely applied in the fields of economic management (Peng \& Dai, 2017; Zhang, 2016; Su et al., 2019) and security (Gul, 2018). Different MCDM methods have been proposed to solve the problems in which the evaluations of alternatives are expressed by PFSs, such as the Pythagorean fuzzy TOPSIS (Zhang \& Xu, 2014), Pythagorean hesitant fuzzy VIKOR (Ali et al., 2018), and Pythagorean fuzzy TODIM (Ren et al., 2016). These MCDM methods show the applicability of PFSs. However, as far as we know, most of these methods adopted either the linear normalization or vector normalization for the evaluation values. They ignored the impact of unit orders of magnitude differences between different criteria. Besides, these Pythagorean fuzzy MCDMs only consider one factor in utility values or secondary ranking (Liao \& Wu, 2019). In addition, the target criteria whose best values are neither maximum nor minimum ones but the values between them are common in practice. However, the existing Pythagorean fuzzy MCDM methods (Zhang \& Xu, 2014; Ali et al., 2018; Ren et al., 2016) were unable to solve the problems with target criteria.

The double normalization-based multiple aggregation (DNMA) method proposed by Liao and Wu (2020) is a new member in the family of utility value-based MCDM methods. It shows higher reliability than other MCDM methods because of the combination of two normalization techniques and three aggregation tools. It can deal with benefit, cost and target criteria at the same time. This method has raised concern since it was proposed (Liao \& Wu, 2020). However, it cannot handle the MCDM problems with the evaluations expressed as PFSs.

Considering the efficiency of PFSs in representing uncertain information and the advantages of the DNMA method in deducing reasonable ranking of alternatives, this study is dedicated to investigating the DNMA method in the Pythagorean fuzzy environment. A novel method named the Pythagorean fuzzy double normalization-based multiple aggregation (PF-DNMA) method is proposed to handle complex MCDM problems. A Pythagorean fuzzy maximum deviation method is developed to derive the weights of criterion and the PF-DNMA method is then used to derive the ranking of alternatives. Finally, we implement the PFDNMA method to select internet financial investment products and illustrate the validity of the proposed method.

The rest of this study is organized as follows: Firstly, we establish a criteria system for the evaluation of internet financial products. Then, the PFS and DNMA method are reviewed to facilitate further discussion. Afterward, we propose the Pythagorean fuzzy maximum deviation method and the PF-DNMA method. A case about Internet financial investment product selection is solved by the proposed method. The paper is closed with some conclusions.

\section{Criteria System Establishment for Internet Financial Product Selection}

To select an appropriate internet financial product, firstly, we need to establish a criteria system, and then the performance of alternatives can be evaluated according to these criteria. In this regard, many studies about internet financial product selection focused on the factors that influence consumer choice (Cai et al., 2015) and consumer behavior (Zhai \& Huang, 2016; Walczak \& PienkowskaKamieniecka, 2018). Cai et al. (2015) pointed out that the return rate, liquidity, threshold height, capital security, policy risk, and convenient payment can be taken as the factors from the consumer perspective. Zhai and Huang (2016) confirmed that the performance expectancy, government e-readiness, social influence, trust and facilitating conditions have significant effects on the financial product investment. Based on the valence framework and innovation diffusion theory, Xia and Hou (2016) proposed a model to capture consumers' intention when using online financial products. They obtained that the relative utility advantage significantly enhanced consumers' intentions to use. The negative effects of application and perceived risk did not affect the intention significantly to use. On the other hand, the reliability and practicability of the Internet financial platform also affected the interests of risk (Hou, 2016). The practicability of website technical factors includes website function and operation, positively impacted perceived risk, psychological risk and social risk.

However, the current research has not measured the relationship between product risk and return. Based on the existing research, we construct a model about the mutual influence among the elements which affect the motivation of consumers' investment from the perspectives of consumers' own factors, product factors, network platform, and other influencing factors. The relationship between factor investment benefit including positive correlation and negative correlation is also given, as shown in Figure 1.

To distinguish the differences between different Internet financial products and maximize the guarantee of investor rights, we invite Internet finance experts to conduct online group meetings and make evaluations. Then, they determine the key factors affecting investors' income from the thirdperson perspective. After discussing, the experts finalize six core evaluation criteria as shown in Table 1.

\section{Preliminaries}

In this section, we review some concepts of PFSs and the process of the DNMA method.

\section{Pythagorean Fuzzy Set}

PFSs are flexible for experts to express their fuzzy evaluation information (Yager, 2014). Let $X$ be an arbitrary non-empty set. A PFS $A$ is described as $A=\left\{\left\langle x, \alpha_{A}(x), \beta_{A}(x)\right\rangle \mid x \in X\right\}$, where $\alpha_{A}(x)$ and $\beta_{A}(x)$ are the Pythagorean membership function and Pythagorean non-membership function, respectively. There is $\left(\alpha_{A}(x)\right)^{2}+\left(\beta_{A}(x)\right)^{2} \leq 1$. The hesitancy degree of the PFS $A$ is expressed as: 
$\gamma_{A}(x)=\sqrt{1-\left(\alpha_{A}(x)\right)^{2}-\left(\beta_{A}(x)\right)^{2}}$. Zhang and $\mathrm{Xu}$ (2014)

called $A=\left(\alpha_{A}(x), \beta_{A}(x)\right)$ a Pythagorean fuzzy number

(PFN) which was written as $A=\left(\alpha_{A}, \beta_{A}\right)$.

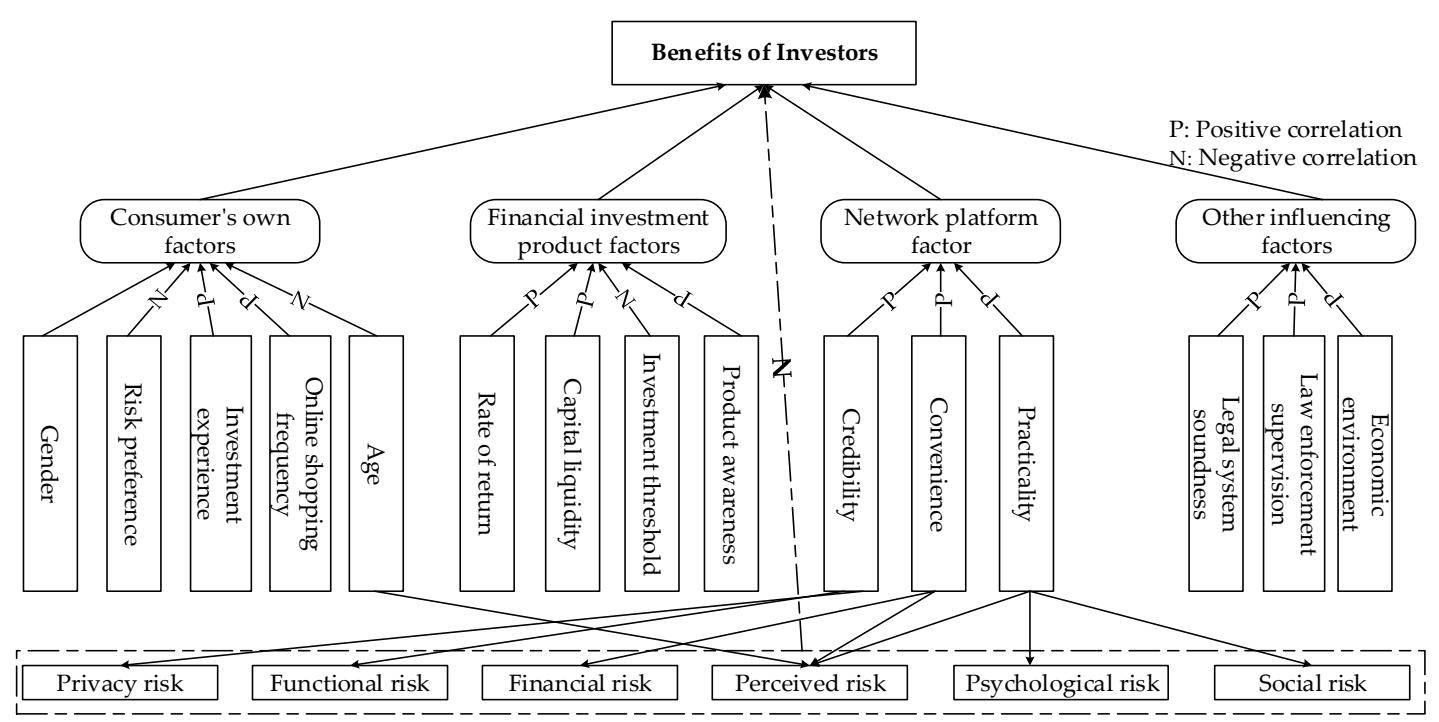

Figure 1. The Factors Affecting Investors' Interests and the Direction of Influence

Table 1

The Evaluation Criteria of Internet Financial Products

\begin{tabular}{|c|c|c|}
\hline Criterion & Type & Meaning \\
\hline$c_{1}$ (Rate of return) & Benefit & The rate of return on the investment, based on the current market price, face value, coupon rate, and \\
distance from the due date.
\end{tabular}

Since the PFS was proposed, scholars have made many achievements related to the PFS, such as Pythagorean fuzzy aggregation operators (Peng \& Yuan, 2016; Ma \& Xu, 2016; Teng et al., 2018; Liu et al., 2017), Pythagorean fuzzy information measures (Li \& Zeng, 2017; Peng et al., 2017), Pythagorean fuzzy MCDM methods (Zhang \& Xu, 2014; Zhang, 2016).

Based on the operations of intuitionistic fuzzy sets, Zhang and $\mathrm{Xu}$ (2014) proposed some operations for PFNs. Let $\eta_{1}=A\left(\alpha_{\eta_{1}}, \beta_{\eta_{1}}\right), \quad \eta_{2}=A\left(\alpha_{\eta_{2}}, \beta_{\eta_{2}}\right)$, and $\eta=A\left(\alpha_{\eta}, \beta_{\eta}\right)$ be three PFNs. We have

1) $\eta^{c}=A\left(\beta_{\eta}, \alpha_{\eta}\right)$

2) $\eta_{1} \oplus \eta_{2}=A\left(\sqrt{\alpha_{\eta_{1}}^{2}+\alpha_{\eta_{2}}^{2}-\alpha_{\eta_{1}}^{2} \alpha_{\eta_{2}}^{2}}, \beta_{\eta_{1}} \beta_{\eta_{2}}\right)$

3) $\lambda \eta=A\left(\sqrt{1-\left(1-\alpha_{\eta}^{2}\right)^{\lambda}},\left(\beta_{\eta}\right)^{\lambda}\right), \lambda>0$

4) $\eta^{\lambda}=A\left(\left(\beta_{\eta}\right)^{\lambda}, \sqrt{1-\left(1-\alpha_{\eta}^{2}\right)^{\lambda}}\right), \lambda>0$

Furthermore, the distance between PFNs was defined as (Ali at al., 2018):

$$
d\left(\eta_{1}, \eta_{2}\right)=0.5 \cdot\left(\left|\alpha_{\eta_{1}}^{2}-\alpha_{\eta_{2}}^{2}\right|+\left|\beta_{\eta_{1}}^{2}-\beta_{\eta_{2}}^{2}\right|+\left|\gamma_{\eta_{1}}^{2}-\gamma_{\eta_{2}}^{2}\right|\right)
$$

For any PFN $\eta=A\left(\alpha_{\eta}, \beta_{\eta}\right)$, the score function was defined as (Zhang \& Xu., 2014) $S(\eta)=\left(\alpha_{\eta}\right)^{2}-\left(\beta_{\eta}\right)^{2}$, where $S(\eta) \in[-1,1]$. The accuracy function was defined as (Zhang $\& \mathrm{Xu}, 2014) a(\eta)=\left(\alpha_{\eta}\right)^{2}+\left(\beta_{\eta}\right)^{2}$, where $a(\eta) \in[0,1]$. For any two PFNs $\eta_{1}$ and $\eta_{2}$, if $s\left(\eta_{1}\right)>S\left(\eta_{2}\right)$, then $\eta_{1}>\eta_{2}$; if $S\left(\eta_{1}\right)<S\left(\eta_{2}\right)$, then $\eta_{1}<\eta_{2}$; if $S\left(\eta_{1}\right)=S\left(\eta_{2}\right)$ and $a\left(\eta_{1}\right)>a\left(\eta_{2}\right)$, then $\eta_{1}>\eta_{2}$; if $S\left(\eta_{1}\right)=S\left(\eta_{2}\right)$ and $a\left(\eta_{1}\right)=a\left(\eta_{2}\right)$, then $\eta_{1} \square \eta_{2}$.

\section{The DNMA Method}

Liao and Wu (2020) proposed the DNMA approach which can solve both the quantitative and qualitative criteria with benefit, cost or target forms at the same time. This approach combines the advantages of the target-based linear normalization and target-based vector normalization. Besides, three kinds of aggregation tools were proposed for different objectives. Then, three subordinate utility values and subordinate ranks were integrated to derive a stable result. This method has strong flexibility, reliability, 
accuracy and robustness. The steps of the DNMA method are briefly described as follows:

Step 1. Normalize the decision matrix $H=\left(A_{i j}\right)_{m \times n}$ into $D=\left(S_{i j}\right)_{m \times n}$ by computing the target-based linear normalization values and target-based vector normalization values through Eqs. (1) and (2), respectively:

$$
\begin{aligned}
& v_{i j}^{1}=1-\frac{\left|A_{i j}-r_{j}\right|}{\max _{i}\left|A_{i j}-r_{j}\right|} \\
& v_{i j}^{2}=1-\frac{\left|A_{i j}-r_{j}\right|}{\sqrt{\sum_{i=1}^{m}\left(A_{i j}\right)^{2}+\left(r_{j}\right)^{2}}}
\end{aligned}
$$

where $r_{j}$ is the target value under criterion $c_{j}$, $r_{j}=\max _{i} A_{i j}$ and $r_{j}=\min _{i} A_{i j}$ are benefit and cost formulas, respectively. Then, normalize the values of different criteria by Eq. (3).

$$
\left\{\begin{array}{l}
v_{i j}^{N 1}=v_{i j}^{1} / \max _{i} v_{i j}^{1} \\
v_{i j}^{N 2}=v_{i j}^{2} / \max _{i} v_{i j}^{2}
\end{array}\right.
$$

Step 2. Calculate three kinds of utility values by three subordinate aggregation models, i.e., the complete compensatory model (CCM), un-compensatory model (UCM) and incomplete compensatory model (ICM) by Eqs. (4)-(6), respectively. Then we can get three subordinate ranks.

$$
\begin{aligned}
& u_{1}\left(A_{i}\right)=\sum_{j=1}^{n} w_{j} v_{i j}^{1} \\
& u_{2}\left(A_{i}\right)=\max _{j} w_{j}\left(1-v_{i j}^{1}\right) \\
& u_{3}\left(A_{i}\right)=\prod_{j}\left(v_{i j}^{2}\right)^{w_{j}}
\end{aligned}
$$

Step 3. Integrate the subordinate ranks, the normalized utility values calculated by Eq. (7) and the weights of three models. Finally, we can get the final ranking of alternatives in descending order of $R C_{i}$, which is calculated by Eq. (8).

$$
\begin{aligned}
& u_{Y}^{N}\left(A_{i}\right)=\frac{u_{Y}\left(A_{i}\right)}{\sqrt{\sum_{i=1}^{m}\left(u_{Y}\left(A_{i}\right)\right)^{2}}, Y=1,2,3} \\
& R C_{i}= \delta_{1} \cdot \sqrt{\Psi\left(u_{1}^{N}\left(A_{i}\right) / \max _{i} u_{1}^{N}\left(A_{i}\right)\right)^{2}+(1-\Psi)\left(\frac{m-r_{1}\left(A_{i}\right)+1}{m}\right)^{2}} \\
&-\delta_{2} \cdot \sqrt{\Psi\left(u_{2}^{N}\left(A_{i}\right) / \max _{i} u_{2}^{N}\left(A_{i}\right)\right)^{2}+(1-\Psi)\left(\frac{r_{2}\left(A_{i}\right)}{m}\right)^{2}} \\
&+\delta_{3} \cdot \sqrt{\Psi\left(u_{3}^{N}\left(A_{i}\right) / \max _{i} u_{3}^{N}\left(A_{i}\right)\right)^{2}+(1-\Psi)\left(\frac{m-r_{3}\left(A_{i}\right)+1}{m}\right)^{2}}
\end{aligned}
$$

where $\delta_{1}, \delta_{2}$ and $\delta_{3}$ are the weights of CCM, UCM and ICM, respectively. $\delta_{1}+\delta_{2}+\delta_{3}=1 . \Psi(\Psi \in[0,1])$ is the relative importance of the subordinate ranks and subordinate utility values.

\section{Methodology: The PF-DNMA Method}

In this section, firstly, we propose a criteria-weighting method, namely the Pythagorean fuzzy maximizing deviation method. Then, we extend the DNMA method to Pythagorean fuzzy environment to rank alternatives. Finally, the framework of the proposed methodology is presented.

\section{Description of the MCDM Problem with Pythagorean Fuzzy Information}

The MCDM problem refers to ranking limited (infinite) alternatives with conflicting and incompatible degrees. It can judge the alternatives and select the best one among many alternatives $D_{i}(i=1,2, \cdots, m)$ based on criteria $c_{j}(j=1,2, \cdots, n)$. The evaluation values of alternatives can be obtained from the discussion and empirical research of expert meetings. At the same time, it empowers the importance of different criteria $w=\left(w_{1}, w_{2}, \cdots, w_{n}\right)^{T}$ where $w_{j} \in[0,1](j=1,2, \cdots, n)$ and $\sum_{j=1}^{n} w_{j}=1$. We can regard the whole evaluation information as a decision-making judgment matrix shown as follows:

$$
Q=\left(D_{i j}\right)_{m \times n}=\begin{gathered}
A_{1} \\
A_{2} \\
\vdots \\
A_{n}
\end{gathered}\left(\begin{array}{ccccc}
H\left(\alpha_{D_{11}}, \beta_{D_{11}}\right) & H\left(\alpha_{D_{12}}, \beta_{D_{12}}\right) & \cdots & H\left(\alpha_{D_{1 n}}, \beta_{D_{1 n}}\right) \\
H\left(\alpha_{D_{21}}, \beta_{D_{21}}\right) & H\left(\alpha_{D_{22}}, \beta_{D_{22}}\right) & \cdots & H\left(\alpha_{D_{2 n}}, \beta_{D_{2 n}}\right) \\
\vdots & \vdots & \vdots & \vdots & \vdots \\
H\left(\alpha_{D_{m 1}}, \beta_{D_{m 1}}\right) & H\left(\alpha_{D_{m 2}}, \beta_{D_{m 2}}\right) & \cdots & H\left(\alpha_{D_{m n}}, \beta_{D_{m n}}\right)
\end{array}\right)
$$

\section{Determining the Optimal Weights of Criteria}

Standard weights play an important role in solving MCDM problems. Sometimes, unreasonable weights can lead to a suspicious or even counter-intuitive decisionmaking result. In real life, the performance of different alternatives under some criteria is small, and these criteria cannot distinguish the advantages and disadvantages of alternatives well. Therefore, it is unreasonable to assign the same weight to different criteria. In other words, the greater the performance differences between alternatives on a criterion are, the greater the importance of this criterion should be. Wang (1997) proposed a maximizing deviation method to determine the weights of criteria, which implies that the criterion with greater deviations should get a larger weight. On the contrast, the criterion which has smaller deviation values among all criteria should be assigned a smaller weight. In this sense, we construct an optimization model by the maximizing deviation method under the Pythagorean fuzzy environment.

The deviation between alternatives $A_{i}$ and $A_{k}$ under criterion $c_{j}$ is given as:

$$
D_{i j}(w)=\sum_{k=1}^{m} d\left(A_{i j}, A_{k j}\right) w_{j}, i=1,2, \cdots, m, j=1,2, \cdots, n
$$

Then, we get the overall deviation value $D_{j}(w)$ of criterion $C_{j}$ as:

$$
D_{j}(w)=\sum_{i=1}^{m} \sum_{k=1}^{m} d\left(A_{i j}, A_{k j}\right) w_{j}, j=1,2, \ldots, n
$$

where $d\left(A_{i j}, A_{k j}\right)=\frac{1}{2}\left(\left|\alpha_{A_{i j}}^{2}-\alpha_{A_{k j}}^{2}\right|+\left|\beta_{A_{i j}}^{2}-\beta_{A_{k j}}^{2}\right|+\left|\gamma_{A_{i j}}^{2}-\gamma_{A_{k j}}^{2}\right|\right)$.

We need to find an optimal weight vector $w$ which can maximize the deviations between alternatives. Thus, we establish a linear programming model as follows:

$$
(M-1)\left\{\begin{array}{l}
\max D(w)=\sum_{i=1}^{m} \sum_{j=1}^{n} D_{i j}(w)=\sum_{i=1}^{m} \sum_{j=1}^{n} \sum_{k=1}^{m} d\left(A_{i j}, A_{k j}\right) w_{j} \\
w \in \theta, \sum_{j=1}^{n} w_{j}=1, w_{j} \geq 0, i=1,2, \cdots, m ; j=1,2, \cdots, n
\end{array}\right.
$$


where $\theta$ denotes the known constraints of criteria weights.

Solving Model (M-1) by MATLAB or LINGO software package, we can obtain the optimal solution $w=\left(w_{1}, w_{2}, \cdots, w_{n}\right)^{T}$.

Sometimes the information about the weights of criteria is unknown, we establish another model to get the optimal solution as follows:

$(M-2)\left\{\begin{array}{l}\max D(w)=\sum_{i=1}^{m} \sum_{j=1}^{n} D_{i j}(w)=\sum_{i=1}^{m} \sum_{j=1}^{n} \sum_{k=1}^{m} d\left(A_{i j}, A_{k j}\right) w_{j} \\ \text { s.t.: } \quad \sum_{j=1}^{n} w_{j}=1, w_{j} \geq 0, j=1,2, \cdots, n\end{array}\right.$

To solve Model (M-2), we establish a Lagrange function:

$$
L(w, \vartheta)=\sum_{i=1}^{m} \sum_{j=1}^{n} \sum_{k=1}^{m} d\left(A_{i j}, A_{k j}\right)+\frac{\vartheta}{2}\left(\sum_{j=1}^{n} w_{j}^{2}-1\right)
$$

where $\vartheta$ is a real number which represents the Lagrange multiplier variable. We calculate the partial derivatives of $L$ as:

$$
\begin{aligned}
\frac{\partial L}{\partial w_{j}} & =\sum_{i=1}^{m} \sum_{k=1}^{m} d\left(A_{i j}, A_{k j}\right)+\vartheta \sum_{j=1}^{n} w_{j}=0 \\
\frac{\partial L}{\partial \vartheta} & =\frac{1}{2} \sum_{j=1}^{n}\left(w_{j}^{2}-1\right)=0
\end{aligned}
$$

From Eq. (14), we obtain

$$
w_{j}=\frac{-\sum_{i=1}^{m} \sum_{k=1}^{m} d\left(A_{i j}, A_{k j}\right)}{\vartheta}, j=1,2, \cdots, n
$$

Putting Eq. (17) into Eq. (16), we have

$$
\vartheta=-\sqrt{\sum_{j=1}^{n}\left(\sum_{i=1}^{m} \sum_{k=1}^{m} d\left(A_{i j}, A_{k j}\right)\right)^{2}}
$$

Setting Eq. (17) and the distance measure into Eq. (16), we can obtain an exact formula for the weights of criteria as:

$$
w_{j}=\frac{\sum_{k=1}^{m} \sum_{i=1}^{m} \frac{1}{2}\left(\left|\alpha_{A_{i j}}^{2}-\alpha_{A_{k j}}^{2}\right|+\left|\beta_{A_{i j}}^{2}-\beta_{A_{k j}}^{2}\right|+\left|\gamma_{A_{i j}}^{2}-\gamma_{A_{k j}}^{2}\right|\right)}{\sqrt{\sum_{j=1}^{m}\left(\sum_{k=1}^{m} \sum_{i=1}^{m} \frac{1}{2}\left(\left|\alpha_{A_{i j}}^{2}-\alpha_{A_{k j}}^{2}\right|+\left|\beta_{A_{i j}}^{2}-\beta_{A_{k j}}^{2}\right|+\left|\gamma_{A_{i j}}^{2}-\gamma_{A_{k j}}^{2}\right|\right)\right)^{2}}}
$$

Finally, we normalize $w_{j}$ and obtain

$$
w_{j}^{*}=\frac{\sum_{k=1}^{m} \sum_{i=1}^{m}\left(\left|\alpha_{A_{i j}}^{2}-\alpha_{A_{k j}}^{2}\right|+\left|\beta_{A_{i j}}^{2}-\beta_{A_{k j}}^{2}\right|+\left|\gamma_{A_{i j}}^{2}-\gamma_{A_{k j}}^{2}\right|\right)}{\sum_{j=1}^{m} \sum_{k=1}^{m} \sum_{i=1}^{m}\left(\left|\alpha_{A_{i j}}^{2}-\alpha_{A_{k j}}^{2}\right|+\left|\beta_{A_{i j}}^{2}-\beta_{A_{k j}}^{2}\right|+\left|\gamma_{A_{i j}}^{2}-\gamma_{A_{k j}}^{2}\right|\right)}
$$

\section{The Pythagorean fuzzy DNMA Method for MCDM}

In this part, we propose the PF-DNMA method which takes the advantages of the target-based linear normalization and target-based vector normalization comprehensively. Three integration models including ranks and the subordinate utility values are proposed. The PF-DNMA method reduces the Pythagorean fuzzy information loss, and the robustness of the results is enhanced. It includes three parts: (1) normalizing the decision matrix by the target-based normalization techniques; (2) combining the normalization values with different aggregation operators; (3) integrating subordinate utility values and ranks.

Firstly, we propose a target-based linear normalization method under the Pythagorean fuzzy environment based on the distance measure as follows:

$$
s_{i j}^{1}=1-\frac{\left|\alpha_{D_{i j}}^{2}-\alpha_{\xi_{j}}^{2}\right|+\left|\beta_{D_{i j}}^{2}-\beta_{\xi_{j}}^{2}\right|+\left|\gamma_{D_{i j}}^{2}-\gamma_{\xi_{j}}^{2}\right|}{\max _{i}\left(\left|\alpha_{D_{i j}}^{2}-\alpha_{\xi_{j}}^{2}\right|+\left|\beta_{D_{i j}}^{2}-\beta_{\xi_{j}}^{2}\right|+\left|\gamma_{D_{i j}}^{2}-\gamma_{\xi_{j}}^{2}\right|\right)}
$$

where $\xi_{j}=\left(\alpha_{\xi j}, \beta_{\xi j}\right)$ is the target value under riterion $c_{j}$ with $\gamma_{\xi j}=\sqrt{1-\left(\alpha_{\xi j}\right)^{2}-\left(\beta_{\xi j}\right)^{2}}$, and $D_{i j}=\left(\alpha_{D_{i j}}, \beta_{D_{i j}}\right)$ is the PFS of alternative $D_{i}$ under criterion $c_{j}$ with $\gamma_{D_{i j}}=$ $\sqrt{1-\left(\alpha_{D_{i j}}\right)^{2}-}\left(\beta_{D_{i j}}\right)^{2}$. It is obvious that $S_{i j}^{1} \in[0,1]$. If $D_{i j}$ is close to $\xi_{j}$, then the value of $S_{i j}^{1}$ is close to 1 ; otherwise it is close to 0 .

As illustrated by Liao and $\mathrm{Wu}$ (2020), the linear normalization may lose the original division between alternatives under a criterion. If we only use the linear normalization values for aggregation, then, the final results may be unreliable. Therefore, we further consider another widely used normalization method to make up for the defect of linear normalization. The target-based vector normalization method under the Pythagorean fuzzy environment is developed as follows:

$$
s_{i j}^{2}=1-\frac{\frac{1}{2} \cdot\left(\left|\alpha_{D_{i j}}^{2}-\alpha_{\xi_{j}}^{2}\right|+\left|\beta_{D_{i j}}^{2}-\beta_{\xi_{j}}^{2}\right|+\left|\gamma_{D_{i j}}^{2}-\gamma_{\xi_{j}}^{2}\right|\right)}{S\left(\sqrt{\sum_{i=1}^{m}\left(\left(\beta_{D_{i j}}\right)^{2}, \sqrt{1-\left(1-\alpha_{D_{i j}}^{2}\right)^{2}}\right)+\left(\left(\beta_{\xi_{j}}\right)^{2}, \sqrt{1-\left(1-\alpha_{\xi_{j}}^{2}\right)^{2}}\right)}\right)}
$$

Obviously, $S_{i j}^{2}=[0,1]$ In fact, the vector normalization cannot eliminate the influence of different value dimensions of criteria, but the linear normalization can solve this problem (Liao \& Wu, 2020)). Therefore, considering both linear and vector normalization is necessary to ensure a reliable decision result.

To eliminate the distribution of different criteria, we need to normalize the data by:

$$
\left\{\begin{array}{l}
s_{i j}^{N 1}=s_{i j}^{1} / \max _{i} s_{i j}^{1} \\
s_{i j}^{N 2}=s_{i j}^{2} / \max _{i} s_{i j}^{2}
\end{array}\right.
$$

Next, the weight vector of criteria is calculated by Eq. (19). Then, we develop the following three aggregation models: CCM, UCM and ICM:

$$
\begin{aligned}
& u_{1}\left(D_{i}\right)=\sum_{j=1}^{n} w_{j} s_{i j}^{N 1} \\
& u_{2}\left(D_{i}\right)=\max _{j} w_{j}\left(1-s_{i j}^{N 1}\right) \\
& u_{3}\left(D_{i}\right)=\prod_{j}\left(s_{i j}^{N 2}\right)^{w_{j}}
\end{aligned}
$$

We have the ranks $R_{1}\left(D_{i}\right)(i=1,2, \cdots, m)$ and $R_{3}\left(D_{i}\right)(i=1,2, \cdots, m) \quad$ by $\quad u_{1}\left(D_{i}\right)(i=1,2, \cdots, m) \quad$ and $u_{3}\left(D_{i}\right)(i=1,2, \cdots, m)$ in descending order, respectively. Besides, we obtain the ranks $R_{2}\left(D_{i}\right)(i=1,2, \cdots, m)$ by $u_{2}\left(D_{i}\right)(i=1,2, \cdots, m)$ in ascending order.

Equation (23) is composed by the arithmetic weighted average operator with target-based linear normalization values. It is a complete compensation model in which the bad performance of an alternative under a criterion can be 
Hongrun Zhang, Huchang Liao, Xingli Wu, Edmundas Kazimieras Zavadskas, Abdullah Al-Barakati. Internet Financial...

eliminate equivalently by the good performance of that alternative under other criteria. This situation is in line with the risk-neutral attitude of decision-makers. Eq. (24) is structured by the maximum-minimum operator with targetbased linear normalization values. It focuses on the worst performance of each alternative. According to this model, we can select the alternative which does not have bad performances under all criteria. This satisfies the risk aversion attitude of decision makers. Most decision makers prefer the alternative which has excellent comprehensive performance without a very bad value under a criterion. This can be achieved by Eq. (25). It is an aggregation operator of incomplete compensation type. Eq. (25) is developed by the geometric weighted operator with target-based vector normalization values. The linear normalization is not used in Eq. (25) since the linear normalization value 0 will invalidate the formula. We can find that, normally, the vector normalization value does not reach 0 . In conclusion, the aggregation models of the PF-DNMA take the advantages of two normalization techniques and three aggregation functions. This makes it flexible to solve complex MCDM problems. We should also note the different between the DNMA method and the MULTIMOORA method in terms of the normalization rules.

To eliminate the different dimensions among the three subordinate utility values, the standardized formula is given as follow:

$$
u_{Y}^{N}\left(D_{i}\right)=\frac{u_{Y}\left(D_{i}\right)}{\sqrt{\sum_{i=1}^{m}\left(u_{Y}\left(D_{i}\right)\right)^{2}}},(Y=1,2,3 ; i=1,2, \cdots, m)
$$

Setting different values for parameter $\Psi$ and $\delta_{y}(y=1,2,3)$ according to different MCDM problems, we can calculate the final scores $R C_{i}(i=1,2, \cdots, m)$ of alternatives by Eq. (27). The final ranks of alternatives are obtained by $R C_{i}(i=1,2, \cdots, m)$ in descending order:

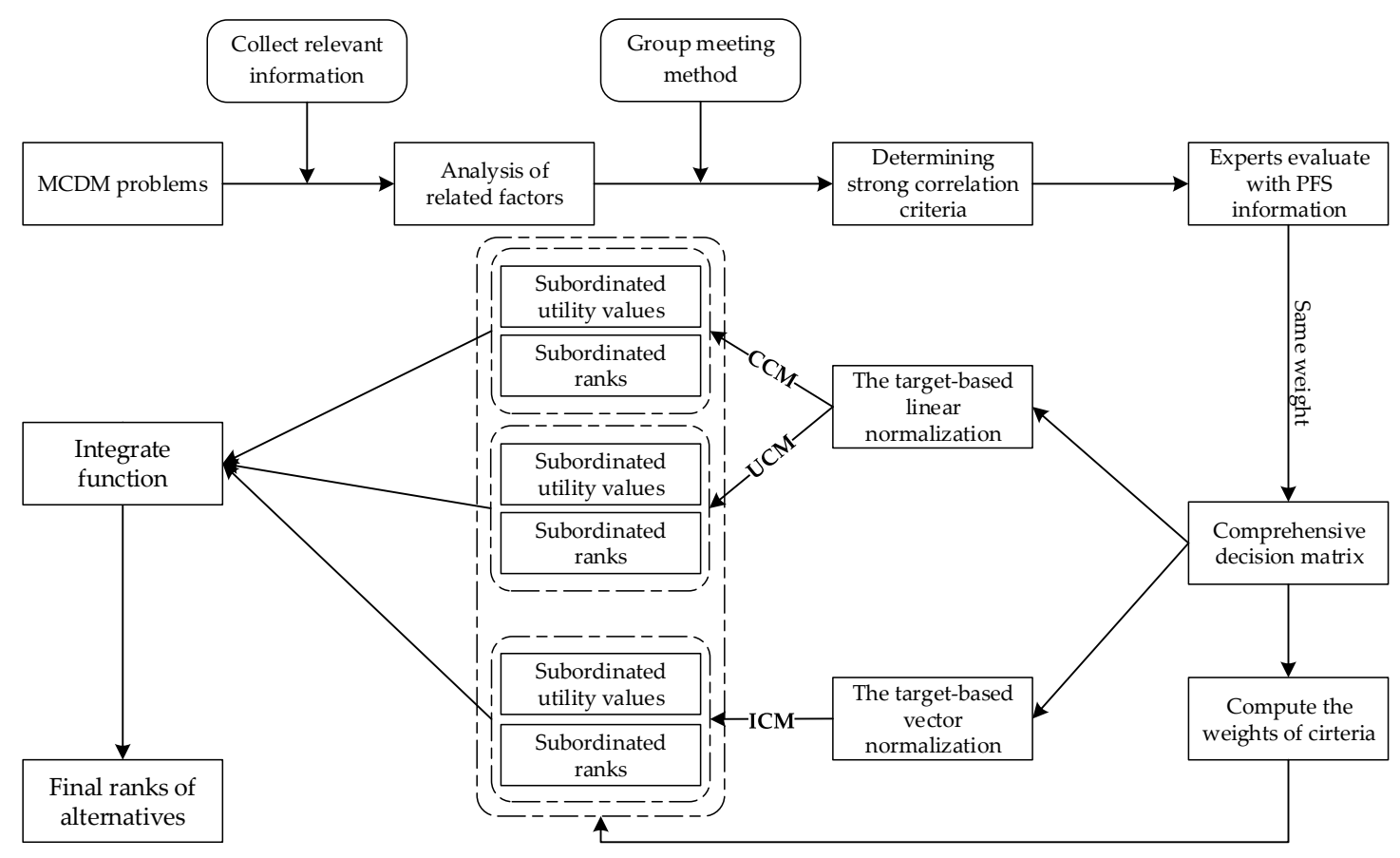

Figure 2. The Framework of the PF-DNMA Method

$$
\begin{aligned}
R C_{i}= & \delta_{1} \cdot \sqrt{\Psi\left(u_{1}^{N}\left(D_{i}\right) / \max _{i} u_{1}^{N}\left(D_{i}\right)\right)^{2}+(1-\Psi)\left(\frac{m-r_{1}\left(D_{i}\right)+1}{m}\right)^{2}} \\
& -\delta_{2} \cdot \sqrt{\Psi\left(u_{2}^{N}\left(D_{i}\right) / \max _{i} u_{2}^{N}\left(D_{i}\right)\right)^{2}+(1-\Psi)\left(\frac{r_{2}\left(D_{i}\right)}{m}\right)^{2}} \\
& +\delta_{3} \cdot \sqrt{\Psi\left(u_{3}^{N}\left(D_{i}\right) / \max _{i} u_{3}^{N}\left(D_{i}\right)\right)^{2}+(1-\Psi)\left(\frac{m-r_{3}\left(D_{i}\right)+1}{m}\right)^{2}}
\end{aligned}
$$

Combining the Pythagorean fuzzy maximizing deviation method with the PF-DNMA, we can construct a comprehensive MCDM method. To facilitate the applications of this method, we summarize the steps of the proposed MCDM method as follows:

Step 1. Collect the relevant information to deeply know about the influence factor of the MCDM problem. Then, sort out and determine the key criteria by the group meeting method. Based on the established criteria, we create the decision matrix $Q=\left(D_{i j}\right)_{m \times n}$, where all the opinions $D_{i j}$ $(i=1,2, \cdots, m ; j=1,2, \cdots, n)$ are given by DMs with Pythagorean fuzzy information.

Step 2. Normalize the comprehensive decision matrix by Eqs. (20)-(21).

Step 3. Suppose the weights of criteria are completely unknown. Then, we can deduce the weights of criteria by Eq. (19).

Step 4. Based on the two target-based normalization techniques, we calculate the subordinate utility values by Eqs. (23)-(25) and get three subordinate ranks. Then, normalize the utility values by Eq. (26).

Step 5. Compute the final scores of alternatives by Eq. (27) and rank the alternatives in descending order.

For clearly understanding of the PF-DNMA method, we summary the procedure in Figure 2 intuitively. 


\section{Case Study}

With the development of Internet and mobile communication technologies, China's economy has been transformed into a high-quality development mode, and an increasing number of traditional enterprises embrace Internet technology. In this situation, a variety of emerging business models have been created, such as the shared economy (Heinrichs, 2013), online medical (Liszka et al., 2006), and mobile finance (Michalski et al., 2018). In recent years, Internet finance has gradually emerged in China and its scale and variety are rapidly growing (Wang et al., 2007). Internet finance is an emerging form combining traditional financial industry with Internet technology. It has a greater impact on the traditional financial industry. Internet companies and financial companies have expanded their Internet finance business. The two representative companies in China are Alibaba and Tencent. At present, Internet finance has many modes such as the third-party payment, big data finance, and Internet financial wealth management products.

Internet financial investment products are the most representative form of the Internet financial model. Since 2013, many Internet companies have cooperated with traditional fund companies to Internet financial investment products to attract users to deposit idle funds into the platform. Various wealth management products are available, such as Alipay, Pat the loan, Yu'e Bao, Cash Bao, Li Cai Tong, Zhong An Online, Google Wallet, and Prosper.
However, because the Internet finance is an emerging format, national and government regulatory measures and systems have not yet formed a good norm. Furthermore, in a relatively anonymous network environment, most investors not only lack professional experience in purchasing Internet financial products, but also are difficult to obtain diversified and complete information about Internet financial products. In turn, it gives ordinary investors a lot of difficulties in choosing Internet financial products. A scientific and effective screening of Internet financial investment products is necessary for investors.

The investors need to consider many factors to measure these products, which is a typical MCDM problem. From what perspectives to evaluate Internet financial wealth management products is critical to solve the problem. Based on the preliminary discussion and analysis, we use the Delphi method to divide the echelon of many Internet financial investment products, and get four first echelon products. We anonymize them and call them $A_{i}(i=1,2,3,4)$. Then, we invite three experts to express their evaluations with Pythagorean fuzzy sets. The individual decision matrices are established as $D_{4 \times 6}^{(k)}(k=1,2,3)$, where $k$ represents the serial number of the experts. Then we give the three experts the same weight for integration, and obtain the comprehensive decision matrix as $D^{N}$.

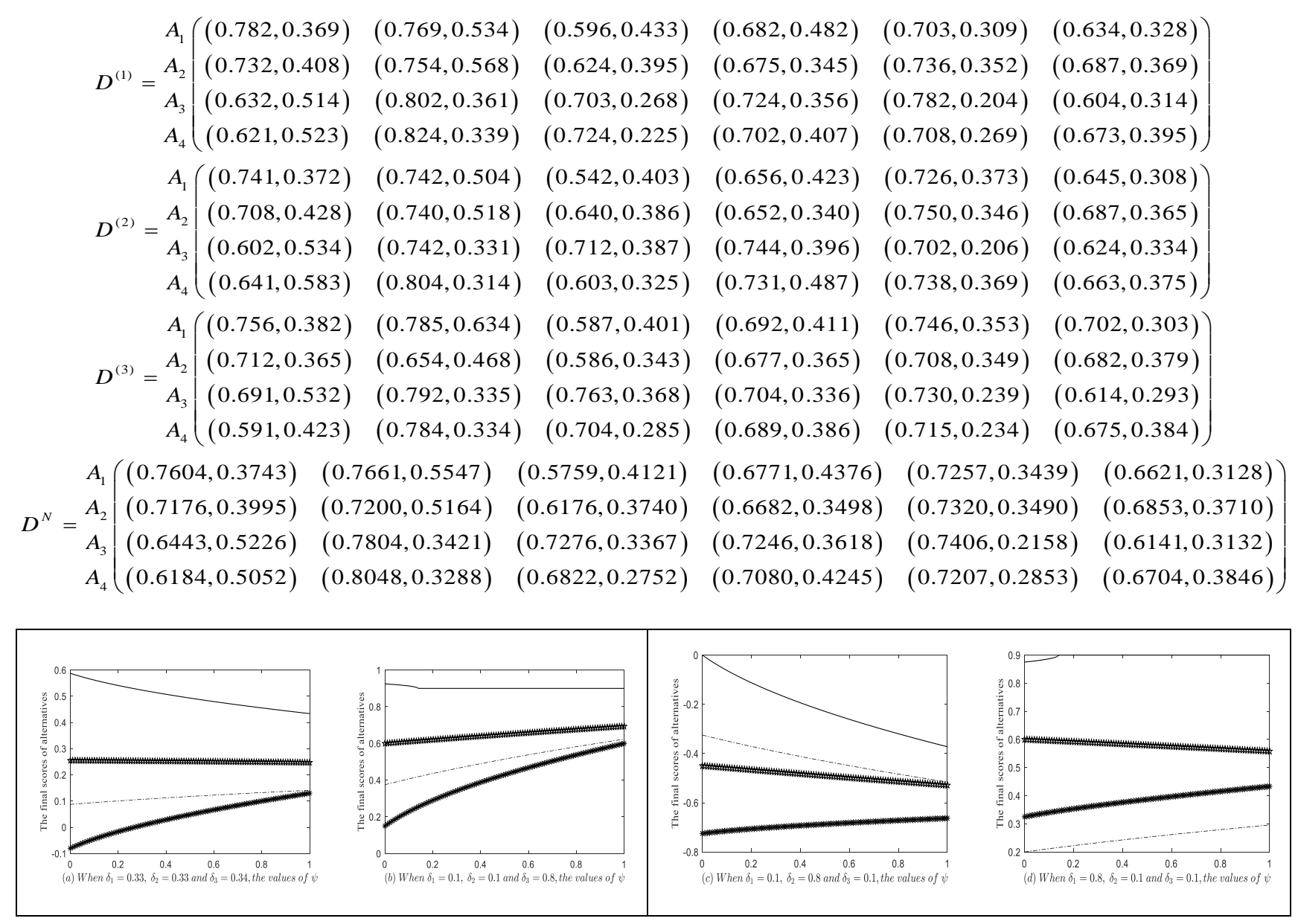

Figure 3. The Preferences of Alternatives with Different Values of the Parameter $\delta$ 
Hongrun Zhang, Huchang Liao, Xingli Wu, Edmundas Kazimieras Zavadskas, Abdullah Al-Barakati. Internet Financial...

\section{Solve the Case by the Pythagorean Fuzzy DNMA Method}

By Eq. (19), we can deduce the weight vector of criteria as $w=(0.2083,0.2425,0.2048,0.1258,0.0846,0.1340)^{T}$. Then, by Eqs. (20)-(22), we obtain two normalization decision matrices as follows:

$$
\begin{aligned}
& A_{1}\left(\begin{array}{llllll}
1.0000 & 0.0000 & 0.0000 & 0.2352 & 0.0465 & 1.0000
\end{array}\right) \\
& \left.D^{N 1}=\begin{array}{c|ccccccc}
A_{2} & 0.6768 & 0.2054 & 0.2513 & 0.0000 & 0.0000 & 0.0000 \\
A_{3} & 0.1669 & 0.8063 & 1.0000 & 1.0000 & 1.0000 & 0.1381 \\
A_{4} & 0.0000 & 1.0000 & 0.4862 & 0.4333 & 0.5368 & 0.1405
\end{array}\right) \\
& \begin{array}{llllllll}
A_{4} & 0.0000 & 1.0000 & 0.4862 & 0.4333 & 0.5368 & 0.1405
\end{array} \\
& \begin{array}{lllllll}
A_{1} & 1.0000 & 0.6109 & 0.3474 & 0.8279 & 0.8623 & 1.0000
\end{array} \\
& D^{N 2}=\begin{array}{c|ccccccc}
A_{2} & 0.8392 & 0.6908 & 0.5114 & 0.7749 & 0.8556 & 0.8112 \\
A_{3} & 0.5856 & 0.9246 & 1.0000 & 1.0000 & 1.0000 & 0.8372 \\
A_{4} & 0.5026 & 1.0000 & 0.6646 & 0.8725 & 0.9331 & 0.8377
\end{array}
\end{aligned}
$$

We calculate the utility values by three aggregation models. The normalized results are given in Table 2 .

Table 2

The Utility Values of Alternatives Derived by PF-DNMA Method

\begin{tabular}{|l|c|c|c|c|c|c|}
\hline & $u_{1}^{N}\left(D_{i}\right)$ & $R_{1}$ & $u_{1}^{N}\left(D_{i}\right)$ & $R_{2}$ & $u_{1}^{N}\left(D_{i}\right)$ & $R_{3}$ \\
\hline$A_{1}$ & 0.4405 & 3 & 1.4312 & 4 & 0.2999 & 4 \\
\hline$A_{2}$ & 0.2840 & 4 & 1.1372 & 2 & 0.3108 & 3 \\
\hline$A_{3}$ & 0.7783 & 1 & 1.0242 & 1 & 0.3730 & 1 \\
\hline$A_{4}$ & 0.5401 & 2 & 1.2294 & 3 & 0.3310 & 2 \\
\hline
\end{tabular}

The parameters can make the alternative more distinguishable. In Fig. 3, when $\delta_{1}=0.33, \delta_{2}=0.33, \delta_{3}=0.34$ , $\delta_{1}=0.1, \delta_{2}=0.1, \delta_{3}=0.8$, the ranking of alternatives is $A_{3} \succ A_{4} \succ A_{1} \succ A_{2}$, but the distances between alternatives are different; when $\delta_{1}=0.1, \delta_{2}=0.8, \delta_{3}=0.1$, the ranking of alternatives is $A_{3} \succ A_{2} \succ A_{4} \succ A_{1} \quad$; when $\delta_{1}=0.8$, $\delta_{2}=0.1, \delta_{3}=0.1 \quad$, the ranking of alternatives is $A_{3} \succ A_{4} \succ A_{1} \succ A_{2}$. We can obtain different rankings with respect to the different values of $\delta_{i}(i=1,2,3)$. In general, the PF-DNMA has flexibility in realistic decision making process.

\section{Comparative Analyses and Discussions}

In what follows, we solve the case by the Pythagorean fuzzy TOPSIS (Zhang \& Xu, 2014) and Pythagorean fuzzy VIKOR. Then we compare the PF-DNMA method with them.

\section{(1) Comparison with the Pythagorean Fuzzy TOPSIS Method}

We apply the Pythagorean fuzzy TOPSIS method (Zhang $\& \mathrm{Xu}, 2014)$ to solve the above case. First, we identity the Pythagorean fuzzy positive ideal solution $\left(P I S^{+}\right)$and the Pythagorean fuzzy negative ideal solution $\left(N I S^{-}\right)$from $D^{N}$ as follows:

$$
\text { PIS }^{+}=\left(\begin{array}{c}
(0.7604,0.3743),(0.8048,0.3288),(0.7276,0.3367), \\
(0.7246,0.3618),(0.7406,0.2158),(0.6621,0.3128)
\end{array}\right)
$$

$$
N I S^{-}=\left(\begin{array}{r}
(0.6184,0.5052),(0.7120,0.5164),(0.5759,0.4121), \\
(0.6771,0.4376),(0.7257,0.3440),(0.6141,0.3132)
\end{array}\right)
$$

Then, by Eq. (28)-(29), we calculate the distances from the Pythagorean fuzzy value of each alternative $A_{i}$ to $P S^{+}$and $N I S^{-}$, respectively. All calculation results are given in Table 3.

$$
\begin{aligned}
& d\left(A_{i}, P I S^{+}\right)=\frac{1}{2} \sum_{j=1}^{n} w_{j}\left(\left|\alpha_{D_{i j}^{N 3}}^{2}-\alpha_{P I S^{+}}^{2}\right|+\left|\beta_{D_{i j}^{N 3}}^{2}-\beta_{P I S^{+}}^{2}\right|+\left|\gamma_{D_{i j}^{N 3}}^{2}-\gamma_{P I S^{+}}^{2}\right|\right) \\
& d\left(A_{i}, N I S^{-}\right)=\frac{1}{2} \sum_{j=1}^{n} w_{j}\left(\left|\alpha_{D_{i j}^{v_{3}}}^{2}-\alpha_{N I S^{-}}^{2}\right|+\left|\beta_{D_{i j}^{v_{3}}}^{2}-\beta_{N I S^{-}}^{2}\right|+\left|\gamma_{D_{i j}^{v_{j}}}^{2}-\gamma_{N I S^{-}}^{2}\right|\right)
\end{aligned}
$$

where $w_{j}(j=1,2,3,4,5,6)$ are the weights of criteria.

Finally, calculate the relative closeness index of each alternative by Eq. (30).

Table 3

Distance between $P I S^{+} / N I S^{-}$and $A_{i}$

\begin{tabular}{|c|c|c|c|c|}
\hline Distance & $A_{1}$ & $A_{2}$ & $A_{3}$ & $A_{4}$ \\
\hline$d\left(A_{i}, P I S^{+}\right)$ & 0.1033 & 0.1088 & 0.0515 & 0.0789 \\
\hline$d\left(A_{i}, N I S^{-}\right)$ & 0.0755 & 0.0667 & 0.1026 & 0.0913 \\
\hline
\end{tabular}

$$
R C_{i}=\frac{d\left(A_{i}, P I S^{+}\right)}{d\left(A_{i}, N I S^{-}\right)+d\left(A_{i}, P I S^{+}\right)}, i=1,2,3,4
$$

Then we can obtain that $R C_{1}=0.5777, R C_{2}=0.6198$, $R C_{3}=0.3344, R C_{4}=0.4636$. There is $A_{3} \succ A_{4} \succ A_{1} \succ A_{2}$. The optimal investment project is $A_{3}$.

\section{(2) Comparison with the Pythagorean Fuzzy VIKOR Method}

We compute the values of group utility measure $G u_{i}$ and individual regret measure $I r_{i}$ by Eq. (31):

$G u_{i}=\sum_{j=1}^{n} w_{j} \frac{d\left(p i s^{+}, D_{i j}^{N}\right)}{d\left(n i s^{-}, p i s^{+}\right)}, I r_{i}=\max _{j}\left(w_{j} \frac{d\left(p i s^{+}, D_{i j}^{N}\right)}{d\left(n i s^{-}, p i s^{+}\right)}\right)$, for $i=1,2,3,4$

where $p^{+} s^{+}=\max _{j}\left(h\left(\alpha_{D_{i j}^{N}}, \beta_{D_{i j}^{N}}\right)\right)$ and

$n i s^{-}=\min _{j}\left(h\left(\alpha_{D_{i j}^{N}}, \beta_{D_{i j}^{N}}\right)\right), \quad w_{j}(j=1,2,3,4,5,6)$ are the weights of criteria.

Then, calculate the value of compromise measure $\mathrm{Cm}_{i}$ by Eq. (32). The calculation results are given in Table 4 .

$$
C M_{i}=\ell \frac{G u_{i}-G u^{-}}{G u^{+}-G u^{-}}+(1-\ell) \frac{I r_{i}-I r^{-}}{I r^{+}-I r^{-}} \text {, for } i=1,2,3,4
$$

where $G u^{-}=\min _{i} G u_{i}, G u^{+}=\max _{i} G u_{i}, \quad I r^{-}=\min _{i} I r_{i}$, $I r^{+}=\max I r_{i} \cdot \ell$ is a parameter, representing the trade-off of the DM.

Considering different parameters, the compromise values of alternatives derived by the Pythagorean fuzzy VIKOR method are shown in Table 4. When $\ell=0.1$, $\ell=0.2, \quad \ell=0.3, \quad \ell=0.4, \quad \ell=0.5, \quad \ell=0.6, \ell=0.7 \quad$ and $\ell=0.8$, the ranking of alternatives is $A_{3} \succ A_{4} \succ A_{2} \succ A_{1}$; when $\ell=0.9$, the ranking of alternatives is $A_{3} \succ A_{4} \succ A_{1} \succ A_{2}$. Thus, the compromise solution is $A_{3}$. 
The Values of $C M_{i}$ with Respect to the Different Values of $\ell$

\begin{tabular}{|l|c|c|c|c|c|c|c|c|c|}
\hline & $\ell=0.1$ & $\ell=0.2$ & $\ell=0.3$ & $\ell=0.4$ & $\ell=0.5$ & $\ell=0.6$ & $\ell=0.7$ & $\ell=0.8$ & $\ell=0.9$ \\
\hline$C M_{1}$ & 0.9523 & 0.9046 & 0.8569 & 0.8091 & 0.8614 & 0.7137 & 0.6660 & 0.6183 & 0.5706 \\
\hline$C M_{2}$ & 0.5347 & 0.5456 & 0.5565 & 0.5674 & 0.5783 & 0.5892 & 0.6001 & 0.6110 & 0.6219 \\
\hline$C M_{3}$ & 0.0266 & 0.0532 & 0.0532 & 0.1064 & 0.1331 & 0.1597 & 0.1863 & 0.2129 & 0.2395 \\
\hline$C M_{4}$ & 0.2798 & 0.2956 & 0.3114 & 0.3272 & 0.3430 & 0.3588 & 0.3746 & 0.3904 & 0.4062 \\
\hline Ranks & 3421 & 3421 & 3421 & 3421 & 3421 & 3421 & 3421 & 3421 & 3412 \\
\hline
\end{tabular}

Note: "3421" in Table 11 describes the ranks of the alternatives, meaning $A_{3} \succ A_{4} \succ A_{2} \succ A_{1}$.

As mentioned above, the optimal alternative selected by the three methods is $A_{3}$. The same results with other methods show that the PF-DNMA method has good availability and effectiveness. The comparative analysis shows that the PF-DNMA method synthesizes the advantages of two kinds of standardization and fully considers the influence of units in quantity and quality dimensions on standardization. By integrating subordinate ranks and utility values, the differences between alternatives are better reflected than the Pythagorean fuzzy TOPSIS and Pythagorean fuzzy VIKOR. At the same time, adjusting parameters are added to the three sub-integration models, and the appropriate values can be selected according to different preference relationships. Another parameter $\Psi(\Psi \in[0,1])$ could control the relative importance of the subordinate ranks and subordinate utility values, which makes the results more flexible.

\section{Conclusion}

DNMA method is one of the utility value-based methods to deal with MCDM problems. It has the characteristics of simple computing process, scientific calculation and flexible application. In this paper, we extended the DNMA method to Pythagorean fuzzy environment to handle the Internet financial investment products selection problems. Through the experiment of parameter change, we can see that the PFDNMA method has better robustness and stability. Based on the literature review, we considered two aspects about investors' behavior and platform risk to establish a criterion system for Internet financial investment. To get objective weights, we introduced a Pythagorean fuzzy maximum deviation method into the PF-DNMA method. The proposed methodology was applied to select the best Internet financial products. For fully illustrating the accuracy of the PF-DNMA method, we compared it with the existing Pythagorean fuzzy TOPSIS and Pythagorean fuzzy VIKOR methods. In three methods, the most frequent ranking is $A_{3} \succ A_{4} \succ A_{1} \succ A_{2}$, and therefore, the PF-DNMA method has good accuracy.

In the future, it is interesting to combine some aggregation operators (Liu \& Wang, 2018; Liu, Chen \& Wang, 2018; Liu \& Wang, 2018) with the PF-DNMA method or extend this method to q-rung orthopair fuzzy sets. Applying the PF-DNMA method to deal with other MCDM problems, such as machine tool selection (Aghdaie, Hashemkhani Zolfani \& Zavadskas, 2013), material selection (Yazdani et al., 2016; Hashemkhani Zolfani, Maknoon \& Zavadskas, 2015), carpenter manufacturer selection (Stevic et al., 2018), is a challenge.

\section{Acknowledgements}

The work was supported by the National Natural Science Foundation of China $(71771156,71971145)$

\section{References}

Aghdaie, M.H., Hashemkhani Zolfani, S. \& Zavadskas, E. K. (2013). Decision making in machine tool selection: an integrated approach with SWARA and COPRAS-G methods. Inzinerine Ekonomika-Engineering Economics, 24(1), 5-17. https://doi.org/10.5755/j01.ee.24.1.2822

Atanassov, K. T. (1986). Intuitionistic fuzzy sets. Fuzzy Sets \& Systems, 20(1), 87-96. https://doi.org/10.1016/S01650114(86)80034-3

Cai, Y. J., Jiang, P. C., \& Jiang, S. (2015). Analysis on the influencing factors for people choosing the Internet financial products-taking Yuebao as example. Journal of Anhui Agricultural Sciences, 20, 111.

Gil-Lafuente, A. M. (2005). Fuzzy Logic in Financial Analysis, Springer, Berlin.

Gul, M. (2018). Application of Pythagorean fuzzy AHP and VIKOR methods in occupational health and safety risk assessment: The case of a gun and rifle barrel external surface oxidation and colouring unit. International Journal of Occupational Safety and Ergonomics. https://doi.org/10.1080/10803548.2018.1492251.

Hashemkhani Zolfani, S., Maknoon, R., \& Zavadskas, E. K. (2015). Multiple Nash equilibriums and evaluation of strategies. New application of MCDM methods. Journal of Business Economics and Management, 16(2), $290-306$. https://doi.org/10.3846/16111699.2014.967715 
Hongrun Zhang, Huchang Liao, Xingli Wu, Edmundas Kazimieras Zavadskas, Abdullah Al-Barakati. Internet Financial...

Heinrichs, H. (2013). Sharing economy: a potential new pathway to sustainability. GAIA-Ecological Perspectives for Science and Society, 22(4), 228-231. https://doi.org/10.14512/gaia.22.4.5

Hou, M. (2016). How online platform work on perceived risk of online financial products. Journal of Zhejiang Gongshang University. https://10.14134/j.cnki.cn33-1337/c.2016.02.010.

Yager, R. R. (2014). Pythagorean membership grades in multi-criteria decision making. IEEE Transactions on Fuzzy Systems, 22, 958-965. https://doi.org/10.1109/TFUZZ.2013.2278989

Yazdani, M. Zavadskas, E. K., Abad, M.D., \& Ignatius, J. (2016). Sensitivity analysis in MADM methods: application of material selection. Inzinerine Ekonomika-Engineering Economics, 27(4), 382-391. https://doi.org/10.5755/ j01.ee.27. 4.14005

Lee, M. C. (2009). Factors influencing the adoption of internet banking: An integration of TAM and TPB with perceived risk and perceived benefit. Electronic Commerce Research and Applications, 8(3), 130-141. https://doi.org/10.1016/j. elerap.2008.11.006

Li, D. Q., \& Zeng, W. Y. (2017). Distance measure of Pythagorean fuzzy sets. International Journal of Intelligent Systems, 33(2), 348-361. https://doi.org/10.1002/int.21934

Liao, H. C., \& Wu, X. L. (2020). DNMA: A double normalization-based multiple aggregation method for multi-expert multi-criteria decision making. Omega, in press, https://doi.org/10.1016/j.omega.2019.04.001.

Liao, H. C., Long, Y. L., Tang, M., Streimikiene, D., \& Lev, B. (2019). Early lung cancer screening using double normalization-based multi-aggregation (DNMA) and Delphi methods with hesitant fuzzy information, Computers \& Industrial Engineering, 136, 453-463. https://doi.org/10.1016/j.cie.2019.07.047

Liszka, H. A., Steyer, T. E., \& Hueston, W. J. (2006). Virtual medical care: How are our patients using online health information. Journal of Community Health, 31(5), 368-378. https://doi.org/10.1007/s10900-006-9019-3

Liu, P. D., \& Liu, J. L. (2018). Some q-rung orthopai fuzzy bonferroni mean operators and their application to multiattribute group decision making. International Journal of Intelligent Systems, 33(2), 315-347. https://doi.org/10. 1002/int.21933

Liu, P. D., \& Wang, P. (2018). Multiple-attribute decision-making based on Archimedean Bonferroni Operators of q-rung orthopair fuzzy numbers. IEEE Transactions on Fuzzy systems, 27(5), 834-848. https://doi.org/10.1109/TFUZZ. 2018.2826452

Liu, P. D., \& Wang, P. (2018). Some q-rung orthopair fuzzy aggregation operators and their applications to multipleattribute decision making. International Journal of Intelligent Systems, 33(2), 259-280. https://doi.org/10.10 02/int. 21927

Liu, P. D., Chen, S. M., \& Wang, P. (2020). Multiple-attribute group decision-making based on q-rung orthopair fuzzy power maclaurin symmetric mean operators. IEEE Transactions on Systems, Man, and Cybernetics: Systems. In press. https://doi.org/10.1109/TSMC.2018.2852948

Liu, Z., Liu, P., Liu, W., \& Pang, J. (2017). Pythagorean uncertain linguistic partitioned Bonferroni mean operators and their application in multi-attribute decision making. Journal of Intelligent \& Fuzzy Systems, 32(3), $2779-2790$. https://doi.org/10.3233/JIFS-16920

Ma, Z. M., \& Xu, Z. S. (2016). Symmetric Pythagorean fuzzy weighted geometric/averaging operators and their application in multicriteria decision-making problems. International Journal of Intelligent Systems, 31(12), 1198-1219. https://doi.org/10.1002/int.21823

Martins, C., Oliveira, T., \& Popovic, A. (2014). Understanding the Internet banking adoption: A unified theory of acceptance and use of technology and perceived risk application. International Journal of Information Management, 34(1), 1-13. https://doi.org/10.1016/j.ijinfomgt.2013.06.002

Merigo, J. M., \& Gil-Lafuente, A. M. (2010). New decision-making techniques and their application in the selection of financial products. Information Sciences, 180(11), 2085-2094. https://doi.org/10.1016/j.ins.2010.01.028

Merigo, J.M., \& Gil-Lafuente, A. M. (2007). Unification point in methods for the selection of financial products, Fuzzy Economic Review, 12(2007), 35-50. https://doi.org/10.25102/fer.2007.01.03

Michalski, G., Blendinger, G., Rozsa, Z., Cierniak-Emerych, A., Svidronova, M., Buleca, J., \& Bulsara, H. (2018). Can we determine debt to equity levels in non-profit organisations? Answer based on Polish case. Inzinerine EkonomikaEngineering Economics, 29(5), 526-535. https://doi.org/10.5755/j01.ee.29.5.19666

Peng, X. D., \& Dai, J. G. (2017). Approaches to Pythagorean fuzzy stochastic multi-criteria decision making based on prospect theory and regret theory with new distance measure and score function. International Journal of Intelligent Systems, 32(11), 1187-1214. https://doi.org/10.1002/int.21896

Peng, X. D., \& Yang, Y. (2015). Some results for Pythagorean fuzzy sets. International Journal of Intelligent Systems, 30(11), 1133-1160. https://doi.org/10.1002/int.21738 
Peng, X. D., Yuan, H. Y., \& Yang, Y. (2017). Pythagorean fuzzy information measures and their applications. International Journal of Intelligent Systems, 32(10), 991-1029. https://doi.org/10.1002/int.21880

Ren, P. J., Xu, Z. S., \& Gou, X. J. (2016). Pythagorean fuzzy TODIM approach to multi-criteria decision making. Applied Soft Computing, 42, 246-259. https://doi.org/10.1016/j.asoc.2015.12.020

Stevic, Z., Vasiljevic, M., Zavadskas, E. K., Sremac, S., \& Turskis, Z. (2018). Selection of carpenter manufacturer using fuzzy EDAS method. Inzinerine Ekonomika-Engineering Economics, 29, 281-290. https://doi.org/10.5755/j0 1.ee.29.3.16818

Su, L., Li, H., Cao, Y., \& Lv, L. (2019). Project Delivery System Decision Making using Pythagorean Fuzzy TOPSIS. Inzinerine Ekonomika-Engineering Economics, 30(4), 461-471.

Teng, F., Liu, Z., \& Liu, P. D. (2018). Some power Maclaurin symmetric mean aggregation operators based on Pythagorean fuzzy linguistic numbers and their application to group decision making. International Journal of Intelligent Systems, 33(9), 1949-1985. https://doi.org/10.1002/int.22005

Walczak, D., \& Pienkowska-Kamieniecka, S. (2018). Gender differences in financial behaviours. Inzinerine EkonomikaEngineering Economics, 29(1), 123-132. https://doi.org/10.5755/j01.ee.29.1.16400

Wang, Y. M. (1997). Using the method of maximizing deviation to make decision for multiindices. Journal of Systems Engineering and Electronics, 8(3), 21-26.

Wang, J. H., Feng, S. C., \& Pan, J. Y. (2007). Design of multi-singing Karaoke system and its application in customer finance-aided service on Internet. In: 2007 IEEE Symposium on Computational Intelligence and Data Mining, 764769. http://10.1109/CIDM.2007.368953.

Xia, H. S., \& Hou, Z. (2016). Consumer use intention of online financial products: the Yuebao example. Financial Innovation, 2(1), 18. https://doi.org/10.1186/s40854-016-0041-X

Zadeh, L. A. (1965). Fuzzy sets. Information \& Control, 8(3), 338-353. https://doi.org/10.1016/S0019-9958(65)90241-X

Zhai, C. J., \& Huang, Y. L. (2016). Exploring consumers' use behavior on internet finance in China: From the perspective of the financial products similar to Yu'e Bao. In: 13th International Conference on Service Systems and Service Management (ICSSSM), 1-6. http://10.1109/ICSSSM.2016.7538659.

Zhang, C., Li, D. Y., \& Ren, R. (2016). Pythagorean fuzzy multigranulation rough set over two universes and its applications in merger and acquisition. International Journal of Intelligent Systems, 31(9), 921-943. https://doi.org/10.100 2/int.21811

Zhang, X. L. (2016). A novel approach based on similarity measure for Pythagorean fuzzy multiple criteria group decision making. International Journal of Intelligent Systems, 31(6), 593-611. https://doi.org/10.1002/int.21796

Zhang, X. L., \& Xu, Z. S. (2014). Extension of TOPSIS to multiple criteria decision making with Pythagorean fuzzy sets. International Journal of Intelligent Systems, 29(12), 1061-1078. https://doi.org/10.1002/int.21676

The article has been reviewed.

Received in April 2019; accepted in February 2020. 